\title{
Substituição do Farelo de Soja pela Farinha de Glúten de Milho na Alimentação de Cabras Leiteiras ${ }^{1}$
}

\section{Luiz Gonzaga Pego de Macedoㄹ, Julio Cesar Damasceno ${ }^{3}$, Elias Nunes Martins ${ }^{3}$, Vicente de Paulo Macedo $^{4}$, Geraldo Tadeu dos Santos ${ }^{3}$, Alencariano José da Silva Falcão ${ }^{5}$, Saul Caldas Neto ${ }^{5}$}

\begin{abstract}
RESUMO - Realizou-se um experimento com cabras Saanen, primíparas, pesando em média, $50 \mathrm{~kg}$, alojadas em baias individuais de $3 \mathrm{~m}^{2}$, objetivando avaliar a substituição da proteína do farelo de soja (FS) pela proteína da farinha de glúten de milho (FGM), na produção e composição do leite, consumo voluntário e níveis de uréia plasmática. O delineamento experimental foi o triplo quadrado latino 4x4, com quatro períodos de 21 dias, sendo 14 dias de adaptação à dieta e sete dias para colheita das amostras. As cabras foram alimentadas e ordenhadas pela manhã e tarde. Os níveis de substituição estudados foram 0, 10, 30 e 50\% de FGM (base na proteína bruta). A substituição do farelo de soja pela farinha de glúten de milho não afetou o consumo ( $\mathrm{kg} /$ dia e \%PV) de matéria seca, proteína bruta e fibra em detergente ácido, mas houve efeito quadrático, para o consumo de fibra em detergente neutro (kg/dia e \% PV). Houve efeito sobre os níveis de uréia plasmática (UP), que foram inferiores para os menores níveis de substituição, sendo os maiores valores de UP observados para o tratamento que possuía somente FS. A produção de leite decresceu linearmente com a inclusão da farinha de glúten de milho. Os níveis de substituição resultaram em decréscimos lineares na produção de gordura (kg/dia), no teor de gordura do leite (\%) e no teor de sólidos totais. Houve efeito quadrático para produção de lactose $(\mathrm{kg} / \mathrm{dia})$, observando-se o menor valor estimado para o nível de substituição de $31,6 \%$. Não foi observado efeito sobre a produção de proteína bruta no leite, cujo valor médio foi de $0,083 \mathrm{~kg} / \mathrm{dia}$. Os teores de proteina bruta, lactose e sólidos totais não sofreram efeito dos níveis de substituição, sendo os valores médios percentuais de 2,$98 ; 4,35$ e $11,51 \%$, respectivamente.
\end{abstract}

Palavras-chave: cabras, leite, farinha glúten de milho, proteína, uréia plasmática

\section{Substitution of Soybean Meal Protein by Corn Gluten Meal Protein in Dairy Goat Feeding}

ABSTRACT - It was carried out an experiment with goats Saanen, on the first lactation, with $50 \mathrm{~kg}$ of body weight, housed in individual stalls of $3 \mathrm{~m}^{2}$, to evaluate the effect of substitution of soybean meal (SM) protein by the protein from the corn gluten flour (CGF), in the milk production, milk composition, voluntary intake and plasmatic urea. The experimental design was the triple Latin square $4 \times 4$, with four periods of 21 days, being 14 days of adaptation to the diet and seven days for samples collection. The goats were fed and milked in the morning and afternoon. The substitution levels studied were: $0,10,30$ and 50\% of CGF (based in the crude protein). The substitution of the soybean meal by CGM did not affect the intake $(\mathrm{kg} / \mathrm{day}$ and $\% \mathrm{BW})$ of dry matter, crude protein and acid detergent fiber, but there was quadratic effect for neutral detergent fiber intake ( $\mathrm{kg} / \mathrm{day}$ and $\% \mathrm{BW})$. There was effect on the levels of plasmatic urea nitrogen (PUN), where the smallest values were in the intermediate levels of substitution, being the biggest values for the treatment with only SM. The milk production decreased lineally with the inclusion of CGM. The substitution levels resulted in lineal decrease in the fat production ( $\mathrm{kg} /$ day), in the milk fat content (\%) and milk total solids content $(\%)$. There was quadratic effect for lactose production, being the smallest value for $31.6 \%$ of substitution level. It was no effect on in crude protein in the milk, which average was $.083 \mathrm{~kg} /$ day. The crude protein content, lactose and total solids did not suffer effect of the substitution levels, being the average values of $2.98,4.35$ and $11.51 \%$, respectively.

Key Words: goat, milk, corn gluten flour, protein, plama urea

\section{Introdução}

Nos últimos anos, vários trabalhos têm sido conduzidos para avaliar os impactos do fornecimento de proteína não degradável no rúmen (PNDR), nas respostas fisiológicas e produtivas de vacas leiteiras, sendo escassos os trabalhos para cabras leiteiras.

Santos (1998), em uma extensa e criteriosa revisão, constatou que a substituição de fontes protéicas de alta degradabilidade ruminal, por outras de elevado

\footnotetext{
${ }^{1}$ Parte da dissertação de mestrado do primeiro autor apresentada ao PPZIDZOIUEM.

${ }^{2}$ Aluno do Programa de Pós-Graduação em Zootecnia-UEM-Maringá. E.mail: gonzaga@teracom.com.br

${ }^{3}$ Professores do Departamento de Zootecnia-UEM, Av. Colombo 5790, CEP: 87020-900, Maringá. Pesquisadores do CNPq.

E.mail: jcdamasceno@uem.br

${ }^{4}$ Aluno do Programa de Pós-Graduação em Zootecnia-UNESP-Botucatu.

${ }^{5}$ Alunos do Programa de Pós-Graduação em Zootecnia-UEM-Maringá.
} 
PNDR, na maioria das vezes, não resultou em variação na produção de leite de vaca. Parte considerável dos estudos relataram efeitos negativos, enquanto que, em poucos trabalhos, observou-se respostas positivas. Isto evidencia a necessidade de outros estudos para melhor esclarecer o assunto.

A síntese de proteína microbiana no rúmen depende da disponibilidade de carboidratos e de nitrogênio no rúmen. Os microrganismos são capazes de reter grande parte da amônia que é liberada no rúmen pela deaminação dos aminoácidos e hidrólise dos compostos nitrogenados. Entretanto, ocorrem condições dietéticas em que a taxa de liberação de amônia no rúmen excede á taxa de fixação pelas bactérias. A falta da sincronização entre a disponibilidade de energia e a liberação de $\mathrm{N}$ no rúmen resulta na ineficiente utilização dos substratos fermentáveis e reduz a síntese de proteína microbiana no rúmen (NRC, 1989).

Animais de alta produção têm respondido, satisfatoriamente, a incrementos na quantidade de proteína metabolizável, via maximização da produção de proteína microbiana e proteína dietética não degradável no rúmen. Estas observações têm sido obtidas em trabalhos que avaliaram o desempenho de animais recebendo dietas com diferentes proporções entre proteína degradável e não degradável no rúmen. Recentemente, a sincronização entre a disponibilidade de energia fermentável e a degradabilidade de nitrogênio no rúmen tem recebido considerável atenção (Sinclair et al., 1993; Sinclair et al., 1995).

Poucos trabalhos na área de nutrição protéica têm sido realizados com cabras leiteiras, mas as vantagens em se equilibrar proteína degradável no rúmen e proteína não degradável têm sido demonstradas.

Trabalhos com cabras leiteiras têm indicado que a racionalização do uso do nitrogênio, através da adequada proporção entre PDR e PNDR, resultam em aumento na produção de leite e este equilíbrio permite, inclusive, redução nos teores de proteína bruta da ração, para níveis inferiores aos recomendados pelo NRC (1981) (Mishra \& Rai, 1996a; Mishra \& Rai, 1996b; Pailan \& Kaur, 1996). Isto tem permitido a racionalização dos custos das dietas, contribuindo, significativamente, com o sucesso econômico da atividade leiteira.

Entre as variáveis consideradas em estudos da nutrição protéica em animais produtores de leite, destacam-se: produção e composição do leite, consumo de nutrientes e níveis de uréia plasmática (Eggum,
1990, Pailan \& Kaur, 1996; Santos, 1998).

As variações observadas nestas variáveis, em relação à nutrição protéica, têm sido função da quantidade total de proteína verdadeira digestível que chega ao intestino, do valor biológico desta proteína e da quantidade de PDR no rúmen, para atender a demanda dos microrganismos (AFRC, 1995).

Devido aos sérios problemas sanitários surgidos a partir do uso de produtos de origem animal na alimentação de animais ruminantes, é pequeno o número de fontes alternativas de proteína não degradável no rúmen disponíveis no mercado. Uma destas fontes é a farinha de glúten de milho, que possui $59 \%$ de proteína não degradável no rúmen.

No processo de beneficiamento do milho são gerados diversos resíduos, dentre eles, a farinha de glúten de milho, obtido por via úmida. Para cada $100 \mathrm{~kg}$ de milho em grãos, são produzidos 62 a $68 \mathrm{~kg}$ de amido, $3 \mathrm{~kg}$ de óleo; $3,2 \mathrm{~kg}$ de farelo de gérmen; $20 \mathrm{~kg}$ de glúten e 4,5 kg de farinha de glúten.

A composição do farelo de glúten de milho, segundo o NRC (1989), é de 91,4\% MS; 66,3\% PB; 5,5\% FB; $8,9 \%$ FDN; $89,0 \%$ NDT; 3,22 EM (Mcal $/ \mathrm{kg} \mathrm{MS}$ ) e $59 \%$ proteína não degradável no rúmen (PNDR).

A baixa degradabilidade no rúmen da farinha de glúten de milho permite a passagem desta para o intestino delgado, sem sofrer o ataque dos microrganismos, aumentando, assim, a eficiência de utilização das fontes de nitrogênio. A farinha de glúten de milho não possui um perfil de aminoácidos equilibrado, o que requer maiores observações, no que se refere às quantidades de aminoácidos presentes no intestino delgado, e, quando necessário, deve-se fazer ajuste dos mesmos (Santos, 1998).

Comercialmente, a farinha de glúten de milho é encontrada no mercado com os nomes de protenose e glutenose 60 (Henrique \& Bose, 1997).

A farinha de glúten de milho tem sido usada em dietas de alta energia para bovinos em fase de terminação, pois contém fibra e proteína de alta digestibilidade e ainda reduz problemas referentes à acidose (Richards et al., 1998).

No Brasil, não há estudos com cabras leiteiras, avaliando diferentes níveis de substituição do farelo de soja pela farinha de glúten de milho, sobre as respostas fisiológicas e produtivas dos animais.

Portanto, este trabalho foi realizado com o objetivo de obter informações técnicas sobre a nutrição protéica de cabras leiteiras, substituindo-se a fonte protéica tradicional de alta degradabilidade ruminal, 
nesta pesquisa, o farelo de soja $(>55 \%$ de degradabilidade), por outra fonte de baixa degradabilidade ruminal, utilizando a farinha de glúten de milho (<40\% de degradabilidade), avaliando-se a resposta animal em relação à produção e composição do leite, consumo voluntário e níveis sangüíneos de uréia plasmática.

\section{Material e Métodos}

O experimento foi desenvolvido no período de janeiro a maio de 2000, no setor de Caprinocultura da fazenda experimental da Universidade Estadual de Maringá, localizada em Iguatemi no município de Maringá - Paraná.

Os animais foram alojados em baias individuais, com piso ripado e área de $3 \mathrm{~m}^{2}$, contendo bebedouros e comedouros com sal mineral à vontade e com acesso ao solário, durante duas horas por dia, no período da manhã.

Foram utilizadas 12 cabras mestiças Saanen, primíparas de aproximadamente 20 meses de idade, com peso vivo médio de $50 \mathrm{~kg}$ e produção média de 2,5 litros de leite, por dia. Os animais foram distribuídos, aleatoriamente, em triplo quadrado latino, $4 \times 4$, sendo quatro tratamentos e quatro períodos de 21 dias, compostos de 14 dias de adaptação e sete dias de colheita.

Os tratamentos consistiram na substituição da proteína do farelo de soja (FS) pela proteína da farinha de glúten de milho (FGM) na proporção de 0 , 10,30 e $50 \%$. As rações foram formuladas, segundo o AFRC (1995), com teor protéico médio de 17,5\%, preparadas semanalmente, peletizadas e armazenadas em sacos previamente identificados, sendo fornecidas à vontade duas vezes ao dia, às $8 \mathrm{~h} 30 \mathrm{e}$ 16h30, garantindo-se sobras de, no mínimo, $15 \%$ e, no máximo, $25 \%$ do fornecido. A cada lote de ração fabricada, foram colhidas amostras que, ao final, constituíram uma amostra composta para análise química. O feno utilizado na composição das rações foi colhido com aproximadamente 52 dias de idade e as análises de fibra em detergente neutro (FDN) variaram de 69,1 a $71,9 \%$, sendo o FDN médio igual a $68,7 \%$ e a fibra em detergente ácido (FDA) variou de 34,6 a $37,1 \%$, com teor médio de $36,2 \%$, enquanto que o teor médio de proteína bruta (PB) do feno, utilizado na formulação da ração total foi de $6,8 \%$ das amostras utilizadas na composição da ração, valores obtidos conforme análises químicas realizadas no Laboratório de Análises de Alimentos do Departamento de Zootecnia.

Os valores da composição química dos alimentos utilizadas nas rações dos tratamentos estão apresentados na Tabela 1.

As cabras foram ordenhadas manualmente, duas vezes ao dia, às 8 e $16 \mathrm{~h}$, pesando-se o leite, obtendo, desta maneira, a produção de leite diária. Colheramse quatro amostras de leite por animal durante cada

Tabela 1 - Ingredientes e composição química (\% na MS) das dietas experimentais

Table 1 - Feedstuffs and chemical composition (\% DM) of the experimental diets

Ingredientes

Feedstuffs
Níveis de substituição da proteína do farelo de soja pela farinha de glúten de milho (\%)

Substitution level of soybean meal protein by protein from gluten corn flour (\%)

\begin{tabular}{|c|c|c|c|c|}
\hline & \multicolumn{4}{|c|}{ protein from gluten corn flour (\%) } \\
\hline & 0 & 10 & 30 & 50 \\
\hline Farelo de soja (kg) (Soybean meal) & 24,00 & 21,80 & 17,10 & 12,40 \\
\hline Milho grão moído (kg) (Corn grain) & 28,70 & 28,80 & 29,20 & 29,60 \\
\hline Farinha de glúten de milho (kg) (Corn gluten fluor) & 0,00 & 1,90 & 5,60 & 9,40 \\
\hline Feno de coastcross (kg) (Coastcross hay) & 45,80 & 46,00 & 46,60 & 47,10 \\
\hline Calcário (kg) (Limestone) & 0,50 & 0,50 & 0,50 & 0,50 \\
\hline Fosfato bicálcico (kg) (Dicalcium phosfate, $\mathrm{kg}$ ) & 1,00 & 1,00 & 1,00 & 1,00 \\
\hline \multicolumn{5}{|l|}{ Nutrientes ${ }^{1}$} \\
\hline \multicolumn{5}{|l|}{ Nutrients } \\
\hline Proteína bruta (\%) (Crude protein, \%) & 17,61 & 17,68 & 17,71 & 17,79 \\
\hline FDN $(\%)(N D F, \%)$ & 64,00 & 62,00 & 61,00 & 63,00 \\
\hline FDA $(\%)(A D F, \%)$ & 46,00 & 45,00 & 47,00 & 46,00 \\
\hline Cinzas $(\%)(A s h, \%)$ & 6,00 & 5,00 & 5,00 & 5,00 \\
\hline
\end{tabular}

${ }^{1}$ Análises realizadas no Laboratório de Nutrição Animal - DZO/UEM.

1 Analyses were performed at the Animal Nutrition Lab-DZO/UEM.

R. Bras. Zootec., v.32, n.4, p.992-1001, 2003 
período, sendo as amostras obtidas da mistura das ordenhas do período da manhã e da tarde, colhidas em dias consecutivos, a partir do 15 o dia de cada período. Essas amostras foram colhidas em tubos especiais, contendo dois comprimidos de conservantes 2-bromo2-nitropropano-1,3diol (BRONOPOL) e foram enviadas semanalmente para análises no laboratório da associação paranaense de criadores de bovinos da raça holandesa (APCBRH), em Curitiba, PR.

As amostras de leite foram analisadas quanto aos teores de proteína bruta, gordura, lactose e sólidos totais, sendo efetuadas em equipamento infravermelho Bentley 2000 (Bentley Instruments, Inc. - ChaskaMN-USA), no Programa de Análise de Rebanho Leiteiros do Paraná.

No último dia de cada período, às $8 ; 10 ; 12 ; 14 \mathrm{e}$ $16 \mathrm{~h}$, foram colhidas amostras de sangue na jugular de cada animal. As amostras, após colhidas em tubos plásticos tipo vacutainer previamente identificados, foram centrifugadas a $3.000 \mathrm{rpm}$, durante 15 minutos para obtenção do plasma sangüíneo, que, posteriormente, foram armazenados em freezer a $20^{\circ} \mathrm{C}$, para serem enviados ao laboratório de análises. As análises dos níveis de uréia plasmática (UP) foram feitas por método enzimático, urease/glutamato/ desidrogenase-GLDH, descrito por Talke e Schubert (1965), no Laboratório de Análises Clínicas na Universidade Estadual de Maringá, Paraná.

O consumo diário de ração por animal foi obtido através da diferença entre as quantidades fornecidas e as quantidades das respectivas sobras, que eram retiradas dos cochos às oito horas da manhã seguinte, separadas para obtenção de uma amostra composta, propiciando assim, material para análises químicas das quantidades de rações consumidas.

As determinações de matéria seca (MS), matéria orgânica (MO) e PB das amostras das rações foram feitas, de acordo com as metodologias citadas por Silva (1990). As determinações de FDN e FDA foram feitas conforme descrito por Van Soest et al. (1991).

O delineamento experimental utilizado foi o triplo quadrado latino $(4 \mathrm{x} 4)$, com quatro tratamentos e quatro períodos e as variáveis produção, composição de leite e consumo de nutrientes foram analisadas pelo SAEG (1997), segundo modelo descrito abaixo:

$$
\mathrm{y}_{\mathrm{ijkl}}=\mu+\mathrm{b}_{1}\left(\mathrm{x}_{\mathrm{i}}-\overline{\mathrm{x}}\right)+\mathrm{b}_{2}\left(\mathrm{x}_{\mathrm{i}}-\overline{\mathrm{x}}\right)^{2}+\mathrm{Q}_{\mathrm{i}}+\mathrm{P}_{\mathrm{k}}+\mathrm{A}_{1} / \mathrm{Q}_{\mathrm{j}}+\mathrm{e}_{\mathrm{ijkl}}
$$

em que $Y_{i j k l}$ valor observado no l-ésimo animal que recebeu o i-ésimo tratamento no j-ésimo quadrado latino; m constante geral; $b_{1}$ e $b_{2}$ coeficientes de regressão linear e quadrático respectivamente; $X_{i}$ níveis de substituição do farelo de soja pela farinha de glúten de milho para $\mathrm{i}=0,10,30$ e $50 \%$; $\mathrm{Q}_{\mathrm{j}}$ é o efeito do j-ésimo quadrado latino; $\mathrm{P}_{\mathrm{k}}$ é o efeito do k-ésimo período; $A_{1} / Q_{k j}$ é o efeito do l-ésimo animal dentro do k-ésimo quadrado latino; $\mathrm{e}_{\mathrm{ijkl}}$ é o erro aleatório associado a cada observação.

O termo "medida repetida" usado neste trabalho refere-se às respostas múltiplas tomadas em seqüência no mesmo animal. Usualmente, as análises estatísticas, aplicadas em ensaios com medidas repetidas, consideram uma estrutura univariada dos dados. Este método trata os dados como se fossem de um delineamento em parcelas sub-divididas (Damon \& Harvey, 1987; Lykos \& Varga, 1997). Porém, as respostas medidas no mesmo animal são correlacionadas, pois contêm uma contribuição comum do animal e suas variâncias, geralmente, mudam com o tempo. Assim, estes padrões de correlação e variação podem gerar uma estrutura de covariância das medidas repetidas (Littell et al., 1998).

A uréia plasmática foi medida cinco vezes ao longo do dia em cada animal. Portanto, os níveis de uréia plasmática foram tratados como medidas repetidas na mesma unidade experimental. Assim, o conjunto de dados gera uma estrutura de variâncias e covariâncias, o qual foi analisado pelo procedimento MIXED do SAS (1996).

Procedeu-se à análise de regressão múltipla para determinar uma superfície de resposta da uréia plasmática em função dos níveis de substituição e do tempo de medição da uréia, segundo a equação abaixo. A análise de regressão múltipla foi realizada pelo procedimento RSREG do SAS (1996) e a superfície de resposta foi obtida pelo procedimento G3D do SAS (1996).

$$
Y_{i j}=b_{0}+b_{1}\left(t_{i}-\bar{t}\right)+b_{2}\left(t_{i}-\bar{t}\right)^{2}+b_{3}\left(m_{j}-\bar{m}\right)+b_{4}\left(m_{j}-\bar{m}\right)^{2}+T * M+e_{i j}
$$

em que $Y_{\mathrm{ij}:}$ nível de uréia plasmática medida no animal i no tempo $\mathrm{j}, \mathrm{b}_{0}$ : intercepto; $\mathrm{b}_{1}$ : coeficiente de regressão linear do nível de substituição $i ; b_{2}$ : coeficiente de regressão quadrático do nível de substituição $i ; b_{3}$ : coeficiente de regressão linear da medida do UP no tempo $\mathrm{j} ; \mathrm{b}_{4}$ : coeficiente de regressão quadrático da medida do UP no tempo $\mathrm{j} ; \mathrm{t}_{\mathrm{i}}$ : efeito dos tratamentos, em que $\mathrm{i}=0 ; 10 ; 30$ e 50 de substituição. $\mathrm{m}_{\mathrm{j}}$ : efeito das medidas, em que $\mathrm{j}=8 ; 10 ; 12 ; 14$ e 16 horas; $\mathrm{e}_{\mathrm{ij}}$ : erro aleatório associado a cada observação. 


\section{Resultados e Discussão}

Os valores de consumo $(\mathrm{kg} / \mathrm{dia}$ e $\% \mathrm{PV})$ de $\mathrm{MS}$, de FDN, de FDA e de PB encontram-se na Tabela 2.

Os níveis de substituição do FS pela FGM não exerceram efeito sobre o consumo de MS, PB e FDA, expresso em $\mathrm{kg} / \mathrm{dia}$ e em \%PV. Observou-se efeito quadrático $(\mathrm{P} \leq 0,05)$ para o consumo de FDN $(\mathrm{kg} / \mathrm{dia}$ e $\% \mathrm{PV}), \mathrm{Y}=0,33843-0,0129935 \mathrm{X}+0,0002355 \mathrm{X}^{2}$ e $Y=3,5564-0,0258132 X+0,00048276 X^{2}$,respectivamente.

Em animais ruminantes, vários mecanismos agem de forma integrada no controle da ingestão de alimentos pelo animal. $\mathrm{O}$ consumo potencial seria aquele determinado pela demanda animal, ou seja, suficiente para atender às exigências de mantença e produção. Já o consumo real, aquele efetivamente praticado pelo animal, dependerá, além das exigências do animal de outros fatores como característica do alimento, condições do meio ambiente e manejo.

$\mathrm{Na}$ presente pesquisa, os animais utilizados e as condições ambientais e de manejo foram as mesmas em todos os tratamentos, de maneira que a principal fonte de variação entre os tratamentos para os componentes nutritivos ingeridos seria a característica do alimento. Em ruminantes, uma das principais características do alimento ligada ao controle de consumo é o teor e qualidade de FDN, o que determinará o potencial de ocupação de volume no rúmen por unidade de alimento consumido (Van Soest, 1994).

Nota-se que, embora a substituição da proteína do FS pela proteína da FGM tenha reduzido o consumo de FDN (efeito quadrático), não foram observados efeitos no consumo de MS. Isto indica, provavelmente, que além do controle físico de consumo, ligado ao consumo de FDN, outros fatores agiram conjuntamente, como qualidade da proteína absorvida (mecanismos pós-ingestivos).

A ausência de efeito sobre o consumo de MS indica, também, que a participação da FGM na dieta, nos níveis estudados, não causou prejuízo à população microbiana do rúmen, por eventual carência de PDR.

Destaca-se que a deficiência de PDR reduziria, proporcionalmente, as quantidades de MS ingerida (AFRC, 1995).

Ruminantes despendem de cinco a dez horas por dia em atividade de alimentação. Sessenta a oitenta por cento da ingestão diária ocorre em duas refeições principais. Durante a refeição principal, a taxa de ingestão é alta no início, tornando-se, continuamente menor, devido ao processo de satisfação, até à saciedade (Faverdin et al., 1995).

Os fatores primários que controlam a ingestão são respostas dos efeitos diretos da dieta, como distensão da parede ruminal, $\mathrm{pH}$ do conteúdo do rúmen, concentração de acetato e a taxa hepática de propionato. Assim como, fatores metabólicos, mediados pelo Sistema Nervoso Central, incluem o tamanho da massa adiposa e a exigência nutricional, como de energia, para satisfazer a mantença e produção (NRC, 1987).

Os nutrientes ingeridos pelo animal relacionam-se

Tabela 2 - Consumo (kg/dia e \%PV) de matéria seca (MS), fibra em detergente neutro (FDN), fibra em detergente ácido (FDA) e proteina bruta (PB) em cabras em lactação, recebendo ração total peletizada com diferentes níveis de substituição da proteína bruta (PB) do farelo de soja (FS) pela PB da farinha de glúten de milho (FGM)

Table 2 - Intake of (kg/day and \%BW) dry matter (MD), neutral detergent fiber (NDF), acid detergent fiber (NDA), crude protein (CP), in lactating dairy goat, receiving pelleted total ration with different substitution levels of soybean meal crude protein by corn gluten flour protein

\begin{tabular}{|c|c|c|c|c|c|c|c|}
\hline \multirow[t]{2}{*}{$\begin{array}{l}\text { Variáveis } \\
\text { Variables }\end{array}$} & \multicolumn{4}{|c|}{$\begin{array}{c}\text { Níveis de substituição (\%) } \\
\text { Substitution levels (\%) }\end{array}$} & \multicolumn{2}{|c|}{$\begin{array}{l}\text { Efeito } \\
\text { Effect }\end{array}$} & \multirow[t]{2}{*}{$\mathrm{CV}(\%)$} \\
\hline & 0 & 10 & 30 & 50 & Lin & Quad & \\
\hline Consumo de MS (kg/dia) (DM intake, $\mathrm{kg} /$ day) & 2,87 & 2,74 & 2,73 & 2,80 & NS & NS & 8,37 \\
\hline Consumo de FDN (kg/dia) (NDF intake, $\mathrm{kg} /$ day) & 1,84 & 1,70 & 1,66 & 1,76 & NS & $* *$ & 8,33 \\
\hline Consumo de FDA (kg/dia) (ADF intake, $\mathrm{kg} /$ day) & 1,32 & 1,23 & 1,28 & 1,28 & NS & NS & 8,46 \\
\hline Consumo de PB (kg/dia) (CP intake, kg/day) & 0,51 & 0,48 & 0,48 & 0,50 & NS & NS & 8,36 \\
\hline Consumo de MS (\%PV/dia) (DM intake, \%BW/day) & 5,60 & 5,61 & 5,30 & 5,34 & NS & NS & 8,21 \\
\hline Consumo de FDN (\%PV/dia) (NDF intake, \%BW/day) & 3,59 & 3,29 & 3,26 & 3,46 & NS & $* *$ & 8,17 \\
\hline Consumo de FDA (\%PV/dia) (ADF intake, \%BW/day) & 2,58 & 2,38 & 2,51 & 2,53 & NS & NS & 8,35 \\
\hline Consumo de PB (\%PV/dia) (CP intake, \%BW/day) & 0,99 & 0,94 & 0,94 & 0,98 & NS & NS & 8,23 \\
\hline
\end{tabular}

Lin = efeito linear, Quad = efeito quadrático, CV = coeficiente de variação, NS = não-significativo.

Lin = linear effect, $Q$ uad $=$ quadratic effect, $C V=$ coefficient of variation, $N S=$ not significant.

$* * \mathrm{P}<0,01$.

R. Bras. Zootec., v.32, n.4, p.992-1001, 2003 
com a satisfação da ingestão de alimentos, através de substâncias que controlam o apetite. Estes nutrientes, ao serem metabolizados, fornecem produtos que atuam de acordo com as necessidades do mesmo, alcançando determinados valores que podem ou não satisfazer um "setpoint", ou seja, um valor determinado pelas necessidades do animal, o que é determinado geneticamente (Tolkamp \& Ketelaars, 1994; Van Soest, 1994).

As rações completas fornecem a relação mais adequada entre volumoso e concentrado, evitando que o animal estabeleça proporção indesejada entre os alimentos. Observações experimentais indicam, em alguns casos, aumento de até $20 \%$ no consumo voluntário, consequentemente, na produção de leite e ganho de peso corporal (Faria, 1993).

Os valores médios para teores (em \%) e produção (kg/dia) de PB, gordura, lactose, sólidos totais do leite de cabras e conversão alimentar, encontram-se na Tabela 3.

A produção de leite decresceu linearmente $(\mathrm{P}<0,05)$ com a inclusão da farinha de glúten de milho nas rações, conforme a equação $\mathrm{Y}=2,88675-0,00317 \mathrm{X}$. Sabe-se que o principal determinante do desempenho animal é o consumo de nutrientes. Como não houve efeito dos tratamentos no consumo de MS, outros fatores aparecem como principais causas da variação da produção de leite. Embora o tratamento controle, seja considerado com menor nível de PNDR, o que teoricamente deveria conduzir a uma menor produção de leite, este fato não ocorreu e, provavelmente, se explica devido ao melhor valor biológico da proteína do farelo de soja, quando comparado com a FGM principalmente ao considerar o perfil de aminoácidos essenciais, com destaque para lisina e metionina, sendo que uma das desvantagens do uso da FGM, é justamente o desequilíbrio destes dois aminoácidos (Santos, 1998).

Os níveis de substituição propiciaram efeito linear decrescente $(\mathrm{P}<0,05)$ para produção de gordura $(\mathrm{kg} /$ dia) e sólidos totais ( $\mathrm{kg} / \mathrm{dia})$, segundo as equações $\mathrm{Y}=0,09682-0,0002457 \mathrm{X}$ e $\mathrm{Y}=0,3223-0,0005099 \mathrm{X}$, respectivamente, e efeito quadrático $(\mathrm{P}<0,05)$, para produção delactose (kg/dia) $Y=0,1306-0,0009 X+0,00001423 X^{2}$, em que o menor valor estimado para esta variável seria obtido no nível de substituição de 31,6\%. Não foi observado efeito do nível de substituição $(\mathrm{P}>0,05)$, sobre a produção de $\mathrm{PB}$, cujo valor médio foi de $0,083 \mathrm{~kg} / \mathrm{dia}$.

O teor de gordura do leite (\%) apresentou efeito linear decrescente $(\mathrm{P}<0,05)$, em função dos níveis de substituição, conforme equação $Y=0,141505$ $0,004842 \mathrm{X}$. Os teores $(\%)$ de PB, lactose e sólidos totais não sofreram efeito dos níveis de substituição, sendo os valores médios percentuais de 2,98; 4,35 e $11,51 \%$, respectivamente.

A provável explicação para a redução dos teores de gordura do leite pode estar relacionada com o

Tabela 3 - Média de produção de leite (kg/dia), médias para teores (\%) e produção (kg/dia) de proteína bruta, gordura, lactose, sólidos totais do leite de cabras, recebendo ração total peletizada com diferentes niveis de substituição da proteina bruta do farelo de soja pela proteína bruta da farinha de glutén de milho.

Table 3 - Means of milk of production ( $\mathrm{kg} /$ day), content (\%) and production ( $\mathrm{kg} /$ day) of crude protein, fat, lactose, total solids in lactating dairy goat, receiving pelleted total ration with different substitution levels of soybean meal crude protein by corn gluten flour protein

\begin{tabular}{|c|c|c|c|c|c|c|c|}
\hline \multirow[t]{2}{*}{$\begin{array}{l}\text { Variáveis } \\
\text { Variables }\end{array}$} & \multicolumn{4}{|c|}{$\begin{array}{c}\text { Níveis de substituição (\%) } \\
\text { Substitution levels (\%) }\end{array}$} & \multicolumn{2}{|c|}{$\begin{array}{l}\text { Efeito } \\
\text { Effect }\end{array}$} & \multirow[t]{2}{*}{$\mathrm{CV}(\%)$} \\
\hline & 0 & 10 & 30 & 50 & Lin & Quad & \\
\hline Proteína bruta (kg/dia) (Crude protein, $\mathrm{kg} /$ day) & 0,085 & 0,084 & 0,080 & 0,083 & NS & NS & 6,96 \\
\hline Gordura (kg/dia) (Fat, kg/day) & 0,098 & 0,096 & 0,083 & 0,088 & $* *$ & NS & 11,72 \\
\hline Lactose (kg/dia) (Lactose, $\mathrm{kg} /$ day) & 0,128 & 0,127 & 0,113 & 0,122 & NS & $* *$ & 10,35 \\
\hline Sólidos totais ( $\mathrm{kg} / \mathrm{dia})$ (Total solids, $\mathrm{kg} /$ day) & 0,337 & 0,332 & 0,304 & 0,316 & $* *$ & NS & 7,17 \\
\hline Proteína bruta(\%) (Crude protein, \%) & 2,95 & 2,98 & 3,03 & 2,99 & NS & NS & 3,65 \\
\hline Gordura $(\%)(F a t, \%)$ & 3,38 & 3,34 & 3,14 & 3,17 & $* *$ & NS & 9,92 \\
\hline Lactose (\%) (Lactose, \%) & 4,41 & 4,42 & 4,21 & 4,38 & NS & NS & 5,74 \\
\hline Sólidos totais (\%) (Total solids, \%) & 11,63 & 11,60 & 11,40 & 11,41 & NS & NS & 3,42 \\
\hline Produção de leite (kg/dia) (Milk production, $\mathrm{kg} /$ day) & 2,91 & 2,88 & 2,67 & 2,79 & $*$ & NS & 7,53 \\
\hline
\end{tabular}

Lin = efeito linear, Quad = efeito quadrático, CV = coeficiente de variação, NS = não-significativo.

$L$ in = linear effect, Quad $=$ quadratic effect, $C V=$ coefficient of variation, $N S=$ not significant.

${ }^{*} \mathrm{P}<0,10 ;{ }^{*} \mathrm{P}<0,01$

R. Bras. Zootec., v.32, n.4, p.992-1001, 2003 
maior aporte de aminoácidos no intestino, conseqüencia da baixa degradabilidade da fonte protéica. Neste caso, a FGM possui perfil de aminoácidos desbalanceados, principalmente entre lisina e metionina, podendo originar um processo de deaminação, em função do aminoácido limitante, condicionando, desta forma, a utilização de aminoácidos como precussores gliconeogênicos e, com aumento da glicose na corrente sangüínea, a insulina aumenta a deposição de gordura no tecido adiposo, em detrimento da mobilização da gordura para glândula mamária. Outra hipótese, pode estar ligada à redução dos precussores dos ácidos graxos formadores de gordura (acetato e butirato), em função de uma provável redução de amônia ruminal, oriunda da baixa degradabilidade protéica no rúmen que, por consequência, reduziria a fermentação ruminal.

McCarthy et al. (1989) avaliaram o efeito de duas fontes de proteínas, sobre a produção, composição do leite em vacas Holandesas multíparas, sendo uma de alta e outra de baixa degradabilidade ruminal, farelo de soja e farinha de peixe, respectivamente. A produção de leite e concentração em $\mathrm{PB}$, não foram influenciadas pelas fontes de PB utilizadas.

A importância da qualidade da proteína na performance de vacas de alta produção de leite fica evidente quando se comparam dietas com níveis semelhantes de PNDR, mas formuladas com suplementos protéicos contendo proteína com balanço adequado em lisina e metionina. Em cinco experimentos analisados por Santos (1996), constatou-se que vacas recebendo farinha de peixe produziram, em média, $10,5 \%$ mais leite, que vacas recebendo protenose de milho. O efeito negativo da proteína de baixa qualidade da protenose de milho (PM) ocorreu, independente do tipo de volumoso fornecido. Estes dados demonstraram que dietas formuladas com valores próximos de PNDR podem resultar em produções de leite diferentes, devido ao impacto da qualidade da fonte protéica, em termos de balanço de aminoácidos essenciais.

Schimidely et al. (1996) estudaram a influência da sincronização da dieta quanto à taxa de degradação dos carboidratos e do nitrogênio e do nível de ingestão de alimentos (2 ou 2,4 kg de MS/dia), sobre a produção e a composição do leite, em cabras leiteiras. Estes autores observaram produção de leite mais elevada para os animais que consumiram a dieta, com alta taxa de degradação ruminal da proteína e dos carboidratos, somente no maior nível de ingestão de MS, não tendo ocorrido mudanças na composição do leite.

Os valores para composição química do leite encontrados neste trabalho, são similares aos observados por Ribeiro (1997), sendo os valores médios de $2,75 \% ; 2,90 \% ; 4,17 \%$ e $10,13 \%$, para teores de gordura, PB, lactose e sólidos totais do leite, respectivamente. Estes valores são próximos aos relatados por Damasceno et al. (1997) e inferiores aos relatados por Chornobai (1998), que encontrou valores para os teores de gordura, $\mathrm{PB}$ e sólidos totais de $3,81 \% ; 3,28 \%$ e $12,30 \%$, respectivamente. Segundo Sung et al. (1999), os valores médios encontrados para a raça Saanen foram $2,6 \%$ de $\mathrm{PB}, 3,3 \%$ de gordura e $4,6 \%$ de lactose.

Ribeiro et al. (1997) verificaram que, durante a produção ao longo do ano, a composição do leite de cabra variou nos seguintes parâmetros: PB, cinzas, gordura e lactose, sendo que estes dois últimos variaram também em função do nível de produção. Voutsinas et al. (1990), na Grécia, também estudaram a variação na composição química e propriedades físico-química do leite de cabras Alpinas, encontrando efeito do estádio de lactação sobre todos os constituintes principais do leite.

A glicose circulante nos ruminantes adultos é substancialmente mais baixa, do que em não ruminantes. Na glândula mamária, a glicose e a galactose sangüíneas são transformadas em lactose pela ligação entre o carbono 1 da galactose com o carbono 4 da glicose, conhecida como o "açúcar do leite". A lactose é produzida pela maioria dos mamíferos, sendo o leite a fonte primária deste açúcar (Champe e Harvey, 1994).

A conversão alimentar não apresentou efeito $(\mathrm{P}>0,05)$, para os diferentes niveis de substituição, em que a média para os diferentes níveis de substituição foi de aproximadamente $0,99 \mathrm{~kg}$ de ração por litro de leite produzido.

Os resultados da concentração de uréia plasmática (mg/dL) são mostrados na Figura 1. Os valores apresentados naFigura 1 foram obtidos a partir da equação: $\mathrm{Y}=85,29-1,75 \mathrm{H}+0,0253 \mathrm{H}^{2}-0,21 \mathrm{~N}+0,0054 \mathrm{~N}^{2}-$ $0,0088 \mathrm{~N}^{*} \mathrm{H}$, em que $\mathrm{N}$ é o nível de substituição e $\mathrm{H}$, o horário de coleta.

Nota-se que os menores valores médios de uréia plasmática (UP) foram encontrados nos maiores níveis de substituição da proteína bruta do FS pela PB da FGM. Em todos os tratamentos, verifica-se que os

R. Bras. Zootec., v.32, n.4, p.992-1001, 2003 
níveis de uréia plasmática reduziram-se durante o dia.

A amônia produzida durante o metabolismo do nitrogênio no rúmen, que não é utilizada pelos microrganismos, é absorvida pela parede ruminal. A amônia é uma molécula nitrogenada tóxica ao organismo, sendo necessário seu transporte até o fígado, pela corrente sangüínea, onde, a partir dela, é sintetizada outra forma de nitrogênio, a uréia. A uréia sintetizada em ruminantes pode ser reciclada para o rúmen, via saliva ou parede ruminal e utilizada novamente para o crescimento microbiano ou, ainda, pode ser excretada via urina. A reciclagem de uréia tem significativa contribuição para os ruminantes, por exemplo, para animais com baixo consumo de PB, isto é, aproximadamente $5 \%$, o que pode representar cerca de $70 \%$ da proteína ingerida.

A principal fonte de nitrogênio para o pool de UP em ruminantes é aquela proveniente da PDR. Portanto, os teores de UP refletiriam a magnitude do $\mathrm{N}$-amoniacal não utilizado pelos microrganismos e absorvido pela parede do rúmen. Esta consideração pode ser válida em explicar os maiores valores de UP nos menores níveis de substituição, em que a PDR, provavelmente, teria sido a maior.

Ressalta-se que há outras fontes de nitrogênio contribuindo com o pool de UP, como por exemplo, deaminação de aminoácidos utilizados como fonte de energia para o animal hospedeiro. Isto, geralmente, ocorre devido ao menor valor biológico da proteína absorvida pelos animais, onde os aminoácidos estão desbalanceados.

Resultados mostram que a inclusão de fontes de proteína de baixa degradabilidade no rúmen, quando em níveis inadequados e de qualidade questionável, pode resultar em excessos de UP, fato não observado neste trabalho. Segundo Hof et al. (1997), a dosagem da uréia plasmática é ferramenta importante para o monitoramento da nutrição protéica em rebanhos leiteiros.

McCarthy et al. (1989), estudando várias dietas, verificaram que o pico de concentração de amônia no líquido ruminal ocorre, aproximadamente, duas horas após a alimentação e que possui alta correlação com os níveis de nitrogênio da UP.

Schimidely et al. (1996) avaliaram metabólitos sangüíneos, utilizando fontes de nitrogênio de alta e de baixa degradação ruminal para cabras leiteiras. Esses autores observaram que a concentração basal de uréia plasmática entre os tratamentos não diferiu, apresentando média aproximada de $36 \mathrm{mg} / \mathrm{dL}$, que é consideravelmente inferior aos níveis encontrados neste

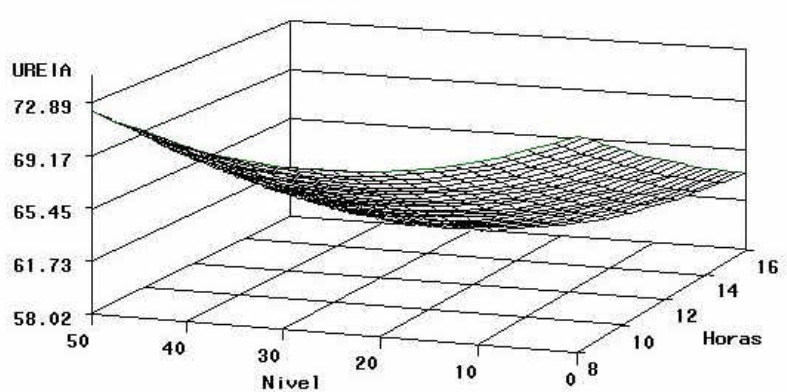

Figura 1 - Concentração de uréia plasmática, em função de diferentes níveis de substituição do farelo de soja por farinha de glúten de milho em diferentes horas do dia.

Figure 1 - Plasma urea concentration in function of different substitution levels of soybean meal protein by corn gluten flour.

trabalho. Isso indica que, no presente trabalho, os níveis de uréia plasmática foram elevados em todas as dietas, mesmo após oito horas da principal refeição fornecida às oito horas da manhã.

Em outrotrabalho, Schimidely etal.(1996) estudaram o efeito da fonte de proteína e o nível de ingestão sobre o metabolismo do nitrogênio em cabras leiteiras. A concentração de uréia plasmática foi maior para as cabras alimentadas com a fonte de proteína de alta taxa de degradação ruminal, o que condiz com os resultados da presente pesquisa.

Andreazzi et al. (1998), estudando os metabólitos sangüíneos de caprinos, relatam valores encontrados para uréia. Estes autores encontraram na literatura como valores normais de uréia sangüínea para caprinos de 13 a $28 \mathrm{mg} / \mathrm{dL}$, diferindo dos encontrados por eles que foi de 7,30 a 9,60 mg/dL. Esta diferença foi explicada como possível interferência da dieta pobre em proteína e/ou rica em gordura, hiper hidratação ou doença hepática aguda ou crônica.

Como pode ser observado, existe uma ligação entre a qualidade e quantidade do material consumido com a produção de leite, sendo o sangue o transportador dos nutrientes pelos órgãos, inclusive para a glândula mamária, o que mostra a importância do estudo conjunto destes parâmetros.

Ribeiro (1997), trabalhando com diferentes fontes de volumosos para cabras leiteiras, encontrou os seguintes valores de concentração de uréia plasmática 
em mg/dL: 94,22; 117,22 e 74,22, para feno de alfafa, silagem de milho e feno de aveia, respectivamente.

Mouro (2001), utilizando fontes de amido com diferentes taxas de degradação ruminal, concluiu que não houve interferências nestes indicadores do metabolismo do nitrogênio e que os níveis médios de uréia no plasma não foram influenciados pelas dietas experimentais, com valores médios de $38,30 \mathrm{mg} / \mathrm{dL}$ de uréia plasmática.

Estes valores são bastante variáveis, quando comparados aos encontrados neste experimento, o que permite sugerir que níveis de uréia plasmática, como indicador do metabolismo protéico, são apenas um entre os diversos parâmetros para estudo do metabolismo protéico. São necessários, ainda, vários trabalhos no sentido de se estabelecerem valores mais precisos.

\section{Conclusões}

Ocorreu redução na produção de leite, gordura, consumo de fibra em detergente neutro e nos níveis de uréia plasmática em função da substituição do farelo de soja pela farinha de glúten de milho.

A substituição da proteína do farelo de soja pela proteína da farinha de glúten de milho na alimentação de cabras leiteiras não é indicada nas condições da presente pesquisa.

\section{Literatura Citada}

ANDREAZZI, M.A.; CONSOLARO, M.E.L.; MORAES, G.V. et al. Avaliação de metabólitos sangüíneos de caprinos machos, alimentados com caroço de algodão. Anuário CCA - 1997-1998. SILVA, O.H., SANTOS, G.T., SENGIK, E. et al. (Ed.).Universidade Estadual de Maringá. Centro de Ciências Agrárias. Maringá - Pr - Brasil. 1998.

AGRICULTURAL AND FOOD RESEARCH COUNCIL - AFRC. Energy and protein requirements of ruminants. Wallingford: 1995. 159p.

CHAMPE, P.C.; HARVEY, R.A. Lippincott's illustrated reviews: biochemistry. 2.ed. Philadelphia: J.B. Lippincott Company, 1994. 446p.

CHORNOBAI, C.A.M. Caracterização físico-química de leite in natura de cabras cruza Saanen, ao longo do período de lactação: Maringá: Universidade Estadual de Maringá, 1998. 100p. Dissertação (Mestrado em Química) - Universidade Estadual de Maringá, 1998.

DAMASCENO, J.C.; FERREIRA, A.C.D.; GEAHL, S.E. Responses of the dairy goats supplemented with different levels of concentrate. Journal of Dairy Science, v.80(suppl.1), p.462, 1997.

DAMON, R.A.; HARVEY, W.R. Experimental design, ANOVA, and regression. New York: Harper and Row, 1987. 320p.

EGGUM, B. Blood urea measurement as a technique for assessing protein quality. Brazilian Journal Nutrition, v.24, p.983-988, 1990.

R. Bras. Zootec., v.32, n.4, p.992-1001, 2003
FARIA, V.P. Rações completas para vacas em lactação, In: PEIXOTO, A.M.; MOURA, J.C.; FARIA, V.P. (Eds.) Confinamento de bovinos leiteiros. Piracicaba: Fundação de Estudos Agrários "Luiz de Queiroz", 1993. p.229-244.

FAVERDIN, P.; BAUMONT, R.; INGVARTSEN, K.L. Control and prediction of feed intake in ruminants. In: JOUNET, M.; GRENET, E.; FARCE, M-H. et al. (Eds.)Recent developments in the nutrition of herbivores. Paris: INRA, 1995. p.95-113.

HENRIQUE, W.; BOSE, M. L. Milho e sorgo. In: SIMPÓSIO SOBRE NUTRIÇÃO DE BOVINOS, 1997, Piracicaba. Anais...Piracicaba: Fundação de Estudos Agrários "Luiz de Queiroz", 1997. p.229-258.

HOF, G.; VERVOORN, M.D.; LENAERS, P.J. et al. Milk urea nitrogen as a tool to monitor the protein nutrition of dairy cows. Journal of Dairy Science, v.80, p.3333-3340, 1997.

LITTELL, R.C., HENRY, P.R., AMMERMAN, C.B. Statistical analysis of repeated measures data using SAS procedures. Journal Animal Science, v.76, p.1216-1231, 1998.

LUCCI,C.S. Nutrição e manejo de bovinos leiteiros. 1.ed. São Paulo: Manole, 1997. 169p.

LYKOS, T.; VARGA, G.A. Varying degradation rates of total nonstructural carbohydrates: effects on nutrient uptake and utilization by the mammary gland in high producing Holstein cows. Journal Dairy Science, v.80, p.3356-3367, 1997.

McCARTHY, R.D. Effects of source of protein and carbohydrate on ruminal fermentation and passage on nutrients of small intestine of lactating cows. Journal Dairy Science, v.72, p.2002-2016, 1989.

MISHRA, S.; RAI, S.N. Effects of different RDP and UDP ratios on voluntary intake, milk production and feed conversion efficiency in lactating goats. Small Ruminant Research, v.20, p.31-38, 1996a.

MISHRA, S.; RAI, S.N. Influence of varying RDP:UDP ratios in diets on digestion, nitrogen utilization and milk production efficiency in goats. Small Ruminant Research, v.20, p.3945, 1996 b.

MOURO, G.F. Substituição do milho pela farinha de mandioca de varredura na alimentação de cabras saanen em lactação: Maringá: Universidade Estadual de Maringá, 2001. 66p. Dissertação (Mestrado em Zootecnia) - Universidade Estadual de Maringá, 2001.

NATIONAL RESEARCH COUNCIL - NRC. Nutrient requirements of goats. Washington, D.C.: National Academy Press, 1981. 91p.

NATIONAL RESEARCH COUNCIL - NRC. Predicting feed intake of food-producing animals. Washington, D.C.: National Academy Press, 1987. 85p.

NATIONAL RESEARCH COUNCIL - NRC. Nutrient requirements of dairy cattle. 6 .ed. Washington, DC.: National Academy Press, 1989. 157p.

PAILAN, G.H.; KAUR, H. Influence of dietary protein content and digestibility on milk yields and blood constituents goats. Small Ruminant Research, v. 20, 47-51, 1996.

REVISTA EXAME, edição $\mathrm{n}^{\circ} 751$, outubro de 2001- pág. 70

RIBEIRO, A.C.; PRATA, L.F.; BARBIERI, M.R. et al. Variação da composição do leite de cabra ao longo do ano, em um criatório da região sudeste do Brasil. In: REUNIÃO ANUAL DA SOCIEDADE BRASILEIRA DE ZOOTECNIA, 34., 1997, Juiz de Fora. Anais... Juiz de Fora: Sociedade Brasileira de Zootecnia, 1997. p.331-333.

RICHARDS, C.J.; STOCKS, R.A.; KLOPFENSTEINK, T.J. et al. Effect of corn gluten feed, supplental protein, and tallow on steer finishing performence. Journal of Animal Science, v.76, p.421428, 1998. 
SANTOS, F.A.P. Conceitos atuais de nutrição protéica. In: SIMPÓSIO SOBRE PRODUÇÃO ANIMAL, 9, 1996, Piracicaba. Anais...Piracicaba: Fundação de Estudos Agrários "Luiz de Queiroz", 1996. p.51.

SANTOS, F.A.P.; SANTOS, J.E.P.; THEURER, C.B. et al. Effects of rumen undegradable protein on dairy cow performance: A 12year literature review. Journal of Dairy Science, v.81, n.12, p.3182-3213, 1998.

SAS INSTITUTE. SAS user's guide for windows environment. 6.12. Cary: 1996. 79p.

SCHIMIDELY, P.; ARCHIMÈDE, H.; BAS, P. et al. Effects of the synchronization of the rate of carbohydrates and nitrogen release of the concentrate on rumen fermentation, plasma metabolites and insulin, in the dry pregnant goat. Animal Feed Science Technology, v.63, p.163-178, 1996.

SILVA, D.J. Análise de alimentos (métodos químicos e biológicos). 2.ed. Viçosa, MG: Universidade Federal de Viçosa, 1990. 165p.

SINCLAIR et al. Effect of synchronizing the rate of dietary energy and nitrogen release on rumen fermentation and microbial protein synthesis is sheep. Journal Agriculture Science, v.120, p.251-263, 1993.

SINCLAIR et al. Effect os synchronizing the rate of dietary energy and nitrogen release in diets with a similar carbohydrate composition on rumen fermentation and microbial protein synthesis in sheep. Journal of Agriculture Science, v.124, p.463-472, 1995.

SUNG, Y.Y.; WU, T.I.; WANG, P.H. Evaluation of milk quality of Alpine, Nubian, Saanen and Toggenburg breeds in Taiwan. Small Ruminant Research, v.33, p.17-23, 1999.
UNIVERSIDADE FEDERAL DE VIÇOSA-UFV. SAEG -Sistema para análise estatística e genética. Versão 7.1. Viçosa, MG: 1997. 150p.(Manual do Usuário).

TALKE, H.; SCHUBERT, G.E. Enzymatische harnstoffbestimmung in blut und serum in optischen test nach warburg. Klin. Wochenschr., v.43, p.174-175, 1965.

TOLKAMP, B.J.; KETELAARS, J.J.M.H. Foraging behaviour programs in ruminants. In: THACKER, P.A. (Ed.). Livestock production in the $21^{\text {st }}$ century: priorities and research needs. p.11-23, 1994.

Van SOEST, P.J. Nutritional ecology of the ruminant. Corvallis: O \& B Inc., 1994. 475p.

Van SOEST, P.J.; ROBERTSON. J.B.; LEWIS, B.A. Methods for dietary fiber, neutral detergent fiber, and nonstarch polysaccharides in relation to animal nutrition. Journal Dairy Science, v.74, n.10, p.3583-3597, 1991.

VIRTANEN, A.I. Milk production of cows on protein-free feed. Journal Dairy Science, v.153, n.744, p.1603-1614, 1966.

VOUTSINAS, L.; PAPPAS, C.; KATSIARI, M. The composition of Alpine goats' milk during lactation in Greece. Journal of Dairy Research, v.57, p.41-51, 1990.

Recebido em: $12 / 04 / 02$

Aceito em: 29/10/02 